\title{
TÉDIO E SENTIDO NA PANDEMIA: UMA ANÁLISE A PARTIR DO PENSAMENTO DE VIKTOR FRANKL
}

Arnin Rommel Pinheiro Braga

Possui graduação em Licenciatura em Filosofia pela Pontifícia Universidade Católica do Paraná (2011) e mestrado em Filosofia pelo Programa de Pós-Graduação em Filosofia da Universidade Federal do Pará (UFPA) - Campus Belém (2019). Tem experiência na área de Filosofia, com ênfase em História da Filosofia, Fenomenologia e Existencialismo.E-mail: arninbraga@gmail.com

\section{RESUMO}

Segundo pesquisa feita nos meses de Abril e Maio de 2020, pelo Sistema de Vigilância de Fatores de Risco e Proteção para Doenças Crônicas por Inquérito Telefônico (Vigitel), do Ministério da Saúde, 20,5\% dos brasileiros que quebraram a quarentena alegaram ter feito isso por um motivo específico: o tédio. Esses dados são preocupantes quando comparados aos altos índices de mortes por COVID-19 nestes mesmos meses. Em outras palavras, muitos brasileiros preferiram arriscar a vida frente à possibilidade de contágio pelo novo Coronavírus, do que conviver com o tédio. Neste sentido, este artigo buscará entender tal comportamento humano, visando explorar de forma fenomenológica as características do tédio tendo por base as análises do pensador austríaco Viktor Frankl, em sua obra Em busca de Sentido. Segundo Frankl, o tédio se apresenta não como uma neurose psicogênica gerada por conflitos psíquicos, mas sim como neurose noogênica, isto é, relacionada com a questão do fracasso existencial e a questão do sentido da existência. Sendo assim, Frankl revela que o tédio - a faceta mais explícita do vazio existencial - pode apresentar uma noodinâmica, ou seja, um conflito entre a realidade concreta e os ideais do indivíduo que o levam a questionar-se sobre o sentido de sua existência. Este sentido não se caracteriza como uma invenção abstrata do sujeito, muito menos como algo externo dado pela cultura e suas tradições. Mas o sentido se mostra e é dado pela própria realidade concreta, que interpela o ser humano e the solicita uma resposta. Quando o ser humano responde a partir da autotranscendência, tal resposta é capaz de conferir sentido à sua existência.

PALAVRAS-CHAVE: Tédio. COVID-19. Sentido da Vida. Frankl. Logoterapia.

BOREDOM AND THE LIFE MEANING DURING THE PANDEMIC: AN 


\title{
ANALYSIS FROM VIKTOR FRANKL'S THOUGHT
}

\begin{abstract}
According to the research done in April and March 2020, by Surveillance System for Risk and Protection for Chronic Diseases (Vigitel), from Ministry of Health, $20,5 \%$ of Brazilians who broke the quarantine claimed to have done this because of a specific reason: boredom. These data are worrying when compared to the right rates of death by COVID-19 in these same months. In other words, many Brazilians preferred risking their lives in face of the possibility of contagion by the new coronavirus, to living with boredom. For the purposes of this essay, the author will seek to understand such human behavior, aiming to explore in a phenomenological way the boredom features based on the Austrian thinker Viktor Frankel, in his work Man's Search for Meaning. According to Frankl, the boredom presents itself not as a psychogenic neurosis generated by psychic conflicts, but as noogenic neurosis, i.e., it is related with the issue of existential failure and the issue of existence meaning. Thus, Frankl reveals that boredom the most explicit facet of the existential void -can present noodynamics, that is, a conflict between the concrete reality and the individuals' ideals that lead them to question themselves about the meaning of their existence. This meaning is not characterized as an abstract invention of the subject, and certainly not as something external given by culture and traditions. But the meaning shows itself and it is given by the own concrete reality, that questions the human beings and asks them an answer. When the human beings answer from self-transcendence, this answer is capable of giving meaning to their existence.
\end{abstract}

KEYWORDS: Boredom. COVID-19. Life meaning. Frankl. Logotherapy.

\section{INTRODUÇÃO}

Desde o primeiro caso confirmado de COVID-19 no Brasil, em 26 de Fevereiro de 2020 , toda a rotina dos brasileiros passou por mudanças radicais. Talvez a maior delas tenha sido o estado de quarentena total ou parcial decretado pelas autoridades civis em muitas cidades e estados, justamente pela mudança de hábitos que esta exigiu: como a reclusão de muitas pessoas em seus próprios lares e o isolamento social. Tal medida surgiu por recomendação da própria Organização Mundial da Saúde (OMS) para a prevenção da proliferação em massa do vírus COVID-19 e teve sua eficácia atestada na própria experiência.

No entanto, constatou-se que esta quarentena nem sempre foi respeitada pelos brasileiros. De acordo com uma pesquisa realizada pelo Ministério da Saúde em parceria com a Universidade Federal de Minas Gerais (UFMG), no período de 25 de Abril a 05 de Maio de 2020,87,1\% das pessoas entrevistadas declararam ter saído de casa e quebrado a quarentena Complexitas - Rev. Fil. Tem., Belém, v. 5, n. 1, p. 67-79, jan./dec. 2020 - ISSN: 2525-4154 
neste período ${ }^{1}$. A pesquisa foi realizada por meio de ligações telefônicas empreendidas pelo Centro de Vigilância de Fatores de Risco e Proteção para Doenças Crônicas por Inquérito Telefônico COVID-19 (Vigitel), e uma das curiosidades constatadas por esta pesquisa reside no fato de que, em meio aos vários motivos alegados pelas pessoas para quebrar a quarentena, 20,5\% afirmaram ter sido o tédio a principal razão².

Em outras palavras, esta pesquisa nos revela que durante os meses de mais contágio e mortes por COVID-19 no Brasil, muitas pessoas preferiram arriscar-se pelas ruas a enfrentar o tédio em suas casas. Dessa forma, este artigo visará analisar a realidade do tédio na quarentena, tendo por base a análise fenomenológico-existencial realizada pelo médico, psicólogo e pensador austríaco Viktor Frankl³(1905-1997) sobre a questão do sentido.

Análise presente em sua obra Em busca de Sentido. O objetivo central deste artigo consiste em apontar como a realidade do tédio - muito presente na vida das pessoas nestes tempos de pandemia de COVID-19 e quarentena - pode revelar-se como oportunidade para o ser humano encontrar-se e sentir-se interpelado pela questão fundamental do sentido da existência.

\section{O QUE É TÉDIO?}

Proveniente do termo latino taedium, a palavra portuguesa "tédio" é definida pelo dicionário como "sentimento de aborrecimento, desgosto e enfado pela demora no desenvolvimento de alguma coisa" (FERREIRA, 2001, p. 664). No entanto, uma análise mais profunda deste estado de espírito do ser humano pode nos revelar alguns dados importantes no esclarecimento do porquê, em tempos de quarentena, muitas pessoas preferiram arriscar-se ao contágio por COVID-19 do que enfrentar o tédio. Neste sentido, o psicólogo humanista Erich Fromm (1900-1980) nos traz a seguinte definição para o tédio, em sua obra A Vida Autêntica (FROMM, 2007, p. 27):

\footnotetext{
${ }^{1}$ Informações obtidas em: MOTA, Thais. Pesquisa revela problemas de sono, alimentação e saúde mental durante pandemia. Disponível em: https://www.otempo.com.br/interessa/pesquisa-revela-problemas-de-sono-alimentacao-e-saude-mental-durantepandemia-1.2343916 Acessado em: 13 de Setembro de 2020.

${ }^{2}$ Informações obtidas em: MOTA, Thais. Pesquisa revela problemas de sono, alimentação e saúde mental durante pandemia. Disponível em: https://www.otempo.com.br/interessa/pesquisa-revela-problemas-de-sono-alimentacao-e-saude-mental-durantepandemia-1.2343916 Acessado em: 13 de Setembro de 2020.

${ }^{3}$ Viktor Emil Frankl (1905-1997) foi um importante pensador judeu austríaco do século XX. Formado em neuropsiquiatria, doutorou-se em filosofia no ano de 1948. Seu pensamento se caracteriza por dialogar temas filosóficos com a psicologia.
} 
(...) é a sensação de futilidade vital, de que vivemos na abundância e carecemos de alegria, de que a vida nos escapa pelas mãos como a areia, de que não sabemos para onde vamos, de que prevalece a confusão e a perplexidade. Recentemente denominou-se um termo científico mais preciso, neurose, que designa esta classe de transtorno. (tradução nossa)

A partir deste olhar mais filosófico, já podemos notar que o tédio se apresenta ao ser humano não somente como o enfado frente à uma espera longa ou demorada, mas principalmente, como uma espécie de transtorno que gera confusão, angústia e a sensação de futilidade vital e perda de sentido. Quando a vida do ser humano é tocada pela realidade do tédio, as coisas parecem perder o significado que anteriormente possuíam, e tudo torna-se perplexidade. Com relação a esta sensação, o filósofo norueguês Lars Svendsen (1970), em sua obra Filosofia do Tédio, relacionará justamente a experiência do tédio do homem moderno e contemporâneo com a perda de um significado pessoal das coisas ao seu redor. Ao ser inserido em um mundo complexo demais e muito além de sua ação e compreensão, o ser humano experimenta a sensação da perda do significado, que o leva ao tédio. Como afirma Svendsen (2005, pp. 27-28):

Acredito que o tédio é resultado de uma falta de significado pessoal, e que isso se deve, em grande medida, precisamente ao fato de que todos os objetos e ações chegam a nós inteiramente codificados, enquanto nós - como descendentes do Romantismo - insistimos num significado pessoal.

Neste sentido, o pensador e psicólogo austríaco Viktor Frankl também analisará o tédio a partir da ótica da experiência da futilidade vital e ausência de significados. Este importante pensador relacionará o tédio com a experiência do vazio existencial. Segundo Frankl (2019, p. 131), a experiência do vazio existencial não é uma realidade nova na humanidade, pois ela parte da própria separação com a natureza que o ser humano experimentou em seu processo evolutivo. Em outras palavras, à medida que o ser humano foi desenvolvendo-se ao longo da

\footnotetext{
Devido a isso, ele é considerado o fundador da terceira escola vienense de psicoterapia: a Logoterapia. Apesar de apresentar seu método clínico em diversas obras, sem dúvida a mais conhecida é seu best-seller internacional. Em busca de sentido (1946), onde ele descreve sua experiência pessoal nos campos de concentração nazistas de Auschwitz e Dachau, além de apontar os aspectos centrais da Logoterapia e a questão do sentido. Foi professor de Neurologia e Psiquiatria na Universidade de Viena e também professor de Logoterapia na Universidade Internacional da Califórnia. Além de ter lecionado em universidades como Harvard, Stanford, Dallas e Pittsburgh. Recebeu o convite de mais de 200 universidades para dar palestras e conferências, inclusive universidades brasileiras, onde esteve em 1984. No âmbito filosófico, Viktor Frankl se enquadra dentro da fenomenologia-existencial, juntamente com outros pensadores como Husserl, Heidegger, Scheler e Rollo May.
} 
história, ele foi perdendo alguns instintos básicos que asseguravam sua existência. Sentindo-se constantemente separado de todo o mundo natural que o rodeia, a humanidade sempre experimentou certo vazio existencial e espanto frente à vida, justamente por não encontrar no próprio instinto nenhum fator referencial interno que possa guiar seus comportamentos. No entanto, Frankl também ressalta que atualmente este vazio existencial e tédio frente à existência estão sendo reforçados por um novo contexto cultural: a crise das tradições e "grandes relatos", que deixam ao homem contemporâneo sem referenciais externos que possam guiar suas ações. Como afirma Frankl (2019, p. 131):

Acresce-se ainda que o ser humano sofreu mais outra perda em seu desenvolvimento mais recente. As tradições, que serviam de apoio para seu comportamento, atualmente vêm diminuindo com grande rapidez. Nenhum instinto lhe diz o que deve fazer e não há tradição que lhe diga o que deveria fazer; às vezes, ele não sabe sequer o que deseja fazer.

Comentando a Viktor Frankl, o filósofo catalão Francesc Torralba (1967) nos apresenta que o ser humano de outros momentos históricos já possuía a resposta da pergunta pela existência a partir das tradições, principalmente aquelas dadas pelas tradições religiosas. A questão principal não era o "por quê de minha existência?", mas o "como devo vivê-la?" para alcançar aquilo que a tradição religiosa dizia ser o sentido da vida (TORRALBA, 2013, pp. 3839). Mas atualmente, a situação cultural se inverteu e o ser humano sabe muito bem como deve viver sua vida para ter um corpo saudável, um bom desenvolvimento econômico, social, etc; mas não sabe mais o porquê de sua existência e o para quê buscar tais coisas. Como afirma Torralba (2013, pp. 38-39):

\footnotetext{
4 Termo cunhado pelo filósofo Jean-François Lyotard. Cf. LYOTARD, J-F. La condición postmoderna. Editora Informe sobre el saber: Madrid, 1984. pp. 10-11; 73-78.
}

\begin{abstract}
No passado, o sentido da vida, o para quê viver, se dava de forma clara, porque no imaginário coletivo existia um grande relato (um gran récit, nas palavras de Jean-François Lyotard) sobre o principio e fim do mundo, uma bela história de amor entre Deus e o ser humano, entre o céu e a terra, que era acreditada e assumida por todos. O sentido não era o problema. O problema era sobreviver mais um dia in hac lachrymarum valle (neste vale de lágrimas). (...) Esse grande relato, tanto do ponto de vista cultural quanto social, se fez, materialmente, em pedaços nos países pós-modernos e secularizados. (...) Como consequiência disso, o cidadão se encontra perplexo. Sabe como viver, como prolongar sua vida até a velhice. Conhece os métodos de vida saudável, como cuidar do seu organismo, como calcular exatamente o número de filhos que deseja procriar, que exercícios deve fazer diariamente para ter uma boa fisionomia, para ter um corpo escultural, mas já não sabe para quê vive, nem para quê está no mundo, nem o que pode esperar depois da sua morte. (tradução nossa)
\end{abstract} Complexitas - Rev. Fil. Tem., Belém, v. 5, n. 1, p. 67-79, jan./dec. 2020 - ISSN: 2525-4154 
Segundo Frankl, é justamente este contexto de não encontrar referenciais nem em si mesmo e nem na cultura ao seu redor que faz com que o ser humano atual recaia no tédio, no vazio existencial e na perda de significado, descritos anteriormente nos fragmentos apresentados de Fromm e Svendsen. Segundo o psicólogo austríaco (2019, p. 131), o tédio se revela como a principal faceta deste vazio existencial atualmente:

\begin{abstract}
O vazio existencial manifesta-se principalmente num estado de tédio. Agora podemos entender por que Schopenhauer disse que, aparentemente, a humanidade estava fadada a oscilar eternamente entre os dois extremos de angústia e tédio. É fato concreto que atualmente está causando e certamente trazendo aos psiquiatras mais problemas do que o faz a angústia. E esses problemas estão se tornando cada vez mais agudos, uma vez que o crescente processo de automação provavelmente conduzirá a um aumento enorme das horas de lazer do trabalhador médio. É lastimável que muitos deles não saberão o que fazer com esse tempo livre adicional.
\end{abstract}

De certo modo, podemos notar aqui um prognóstico profético de Frankl, visto que uma das características do período de quarentena para muitas pessoas foi o tempo livre. Frente a tanto tempo livre longe da rotina de trabalho, muitas pessoas não souberam o que fazer e, consequentemente, foram invadidas pelo tédio. Segundo Frankl, o tédio não é apenas o não saber o que fazer com o tempo livre, mas ele revela algo mais profundo que ele chamou de neurose noogênica (FRANKL, 2019, pp. 126-127). Uma "neurose noogênica" é um transtorno que não é causado por conflitos entre impulsos e instintos, tal como ocorre nas neuroses psicogênicas, mas surge de problemas existenciais como a frustração da vontade de sentido.

Aqui Frankl relaciona então o problema do tédio com a questão do sentido da existência. O tédio brota a partir da frustração do ser humano com os próprios caminhos que sua existência está trilhando. Caminhos estes que muitas vezes entram em conflito com o ideal de existência pensado pelo indivíduo. Essa frustração existencial com a vida muitas vezes é ocultada ou negligenciada por uma rotina acelerada de trabalho e distrações com a vida social. No entanto, a pandemia do COVID-19, juntamente com o estado de isolamento social proveniente da quarentena, fez com que muitas pessoas não pudessem mais recorrer a estes subterfúgios de fuga frente à frustração existencial. E o resultado disso foi o tédio: a constatação de que a vida parece não ter sentido.

No entanto, Frankl aponta que é justamente essa "neurose noogênica" do tédio que desperta no ser humano o que ele chama de noodinâmica (FRANKL, 2019, pp. 129-130). Em outras palavras, Frankl ressalta que o caminho para uma saúde mental e vida com sentido deve 
passar por uma constante dinâmica de tensão dentro do indivíduo. Tensão esta onde ele constantemente contrasta aquilo que ele já alcançou e aquilo que ele ainda almeja alcançar. Tal como afirma o autor (2019, p. 30): “O ser humano precisa não de homeostase, mas daquilo que chamo de 'noodinâmica', isto é, da dinâmica existencial num campo polarizado de tensão, onde um pólo está representado por um sentido a ser realizado e o outro pólo, pela pessoa que deve realizá-1o".

Neste sentido, Frankl ressalta que, apesar de o tédio ser uma experiência que brota da constatação dolorosa de que não nos tornamos aquilo que desejávamos (frustração existencial), não devemos fugir dele. Pelo contrário, o tédio é o ponto de partida para a questão séria sobre o sentido da existência. Nisto consiste a "noodinâmica".

Paradoxalmente, quando o ser humano se percebe submerso no tédio e experimentando a sensação de vazio existencial, surge também dentro dele o desejo ardente de encontrar um sentido à vida, de encontrar-se com uma realidade que possa fazer-lhe simplesmente mudar e recuperar o brilho e a esperança que antes movia suas ações e que agora, por vários motivos, parece que está adormecida. Surge dentro de cada pessoa o que Frankl chama de vontade de sentido:

A busca do indivíduo por um sentido é a motivação primária em sua vida, e não uma "racionalização secundária" de impulsos instintivos. Esse sentido é exclusivo e específico, uma vez que precisa e pode ser cumprido somente por aquela determinada pessoa. Somente então esse sentido assume uma importância que satisfará sua própria vontade de sentido. Alguns autores sustentam que sentidos e valores são "nada mais que mecanismos de defesa, formações reativas e sublimações". Mas, pelo que toca a mim, eu não estaria disposto a viver em função dos meus "mecanismos de defesa". Tampouco estaria pronto a morrer simplesmente por amor às minhas "formações reativas". O que acontece, porém, é que o ser humano é capaz de viver e até morrer por seus ideais e valores! (FRANKL, 2019, pp. 124-125).

Dessa maneira, a "vontade de sentido" é uma força primária que move todo ser humano a continuar em busca, ao invés de entregar-se ao tédio. No entanto, esta "vontade de sentido" pode ficar oculta, negligenciada, adormecida. Faz-se necessário despertá-la. E os meses de quarentena, acompanhados do aumento de pessoas com depressão e ansiedade, revelam isso. Um estudo realizado pela Universidade Estadual do Rio de Janeiro (UERJ) entrevistou, por meio de um questionário online, a cifra de 1.460 pessoas nos períodos de 20 a 25 de Março e 15 a 20 de Abril. Os resultados da pesquisa foram alarmantes: constatou-se um aumento em 50\% 
dos casos de depressão; e $80 \%$ nos casos de ansiedade ${ }^{5}$. Neste sentido, mais do que nunca o ser humano deve despertar para a pergunta pelo sentido. Deve tomar consciência de sua noodinâmica - desta tensão entre tédio e vontade de sentido - para assim reencontrar significado em sua existência. No entanto, a pergunta agora é: como? É o que este artigo buscará responder a seguir.

\section{A QUESTÃO DO SENTIDO DA EXISTÊNCIA}

Ao abordar a questão do sentido, uma das primeiras considerações de Frankl (2019, p. 133) é afirmar que tal realidade não é subjetiva, isto é, uma mera invenção abstrata do sujeito. Em outras palavras, o autor austríaco informa que não se trata de cada ser humano inventar ou simplesmente escolher um sentido para sua vida, à maneira de um objetivo ou uma meta. $\mathrm{O}$ sentido da vida não é uma mera abstração do pensamento humano. Considerar a questão do sentido da existência a partir desta perspectiva seria, segundo Frankl (2019, p. 133), cair em um idealismo que não seria capaz de resolver o problema do tédio, visto que os objetivos inventados por nós podem ou não serem realizados. Se partirmos do pressuposto de que o sentido da vida é algo abstrato, um constructo da mente inventado por cada ser humano, será então inevitável a frustração existencial constante, porque a vida se mostra sempre de forma muito distinta aos nossos ideais formulados racionalmente.

A partir disso, poderíamos então dizer que o sentido da vida - ao não ser uma mera abstração do sujeito - deve ser dado pela realidade externa ao sujeito, ou seja, pela sociedade e pelas tradições. No entanto, Frankl também discordará dessa interpretação. Segundo ele (2019, p. 133), nenhuma instituição, tradição, cultura ou sociedade pode responder a pergunta do sentido da existência no lugar do próprio sujeito questionador. Pois como foi afirmado anteriormente, as tradições e culturas também se desfazem com o tempo e com as mudanças históricas. Em alguns momentos históricos elas podem ter apresentado um caminho mais explícito de sentido para as pessoas; em outros momentos históricos - como o nosso - as respostas dadas por essas tradições se vêm apagadas; mas independentemente do momento histórico, jamais uma tradição pode tirar o protagonismo da pessoa na pergunta pelo sentido da existência.

\footnotetext{
${ }^{5}$ Informações obtidas em: CHALET, Aline. Depressão e ansiedade aumentaram até 80\% na quarentena, diz pesquisa. Disponível em: https://noticias.r7.com/saude/depressao-e-ansiedade-aumentaram-ate-80-na-quarentenadiz-pesquisa-22072020 Acessado em: 13 de Setembro de 2020.
} 
Ora, se o sentido da existência não provém de uma invenção abstrata do sujeito e muito menos das normativas pregadas pelas tradições, de onde virá então a resposta para a questão do sentido da vida? Segundo Frankl, a partir da escuta da própria realidade:

\begin{abstract}
Uma vez que cada situação na vida constitui um desafio para a pessoa e lhe apresenta um problema para resolver, pode-se, a rigor, inverter questão pelo sentido da vida. Em última análise, a pessoa não deveria perguntar qual o sentido da sua vida, mas antes deve reconhecer que é ela que está sendo indagada. Em suma, cada pessoa é questionada pela vida; e ela somente pode responder à vida respondendo por sua própria vida; à vida ela somente pode responder sendo responsável. Assim, a logoterapia vê na responsabilidade (responsibleness) a essência propriamente dita da existência humana. (FRANKL, 2019, pp. 133-134)
\end{abstract}

Logo, segundo o autor, o sentido da vida não é inventado pelo individuo ou por alguma tradição externa a ele, mas o sentido da existência se mostra ao sujeito quando este se deixa interpelar pela realidade concreta em que vive e dá uma resposta à mesma. Sua resposta a esse apelo da realidade concreta é o que dá sentido para sua existência. Desse modo, dirá Frankl (2019, p. 133), não há uma norma geral que defina de forma abstrata e universal o sentido da vida para a humanidade. $\mathrm{O}$ que há são as realidades objetivas que cada indivíduo vivencia e a interpelação que estas fazem a ele. Frankl dirá que perguntar por um sentido geral que sirva para todo ser humano é como perguntar para um jogador de xadrez qual é a jogada perfeita. Não há uma jogada de xadrez perfeita para todas as ocasiões, porque as jogadas perfeitas surgem a partir da realidade de cada jogo. De modo análogo ocorre com a existência humana: não há um sentido para a vida que se aplique a todo ser humano, o que há são as situações da vida que exigem de cada ser humano uma resposta, e essa resposta é capaz de gerar um sentido para a existência (FRANKL, 2019, p. 133).

A partir dessas considerações de Frankl, poderia-se objetar que sua interpretação sobre o sentido da existência não passa de um jogo de palavras onde ele inverte as coisas: "não é o ser humano que questiona a vida, mas é a vida quem questiona o ser humano". Recaindo, assim, em um mero silogismo e, na pior das hipóteses, em um mero discurso motivacional e de autoajuda. No entanto, o pensamento de Frankl e sua teoria clínica - a logoterapia - colocam na realidade concreta o acento para a questão do sentido não por mero capricho, mas porque eles se fundamentam no método fenomenológico de Edmund Husserl (1859-1938) e de Max Scheler (1874-1928).

O método fenomenológico elaborado por Husserl foi revolucionário justamente porque ele devolveu ao sujeito pensante a capacidade de captar a realidade objetiva a partir de uma 
nova atitude: "retornar as coisas mesmas" (HUSSERL, 1976, §2, p.218, tradução nossa). Em outras palavras, Husserl afirmava que a realidade pode ser captada pela consciência do sujeito porque esta possui uma intencionalidade, isto é, ela está aberta, nunca é mera abstração ou algo fechado, mas é sempre consciência de alguma coisa (HUSSERL, 1929); enquanto os objetos exteriores a consciência também estão em relação de abertura (relação intencional) mostrandose tais como são à consciência do sujeito. Desse modo, o método fenomenológico permite a realização de uma mudança radical de atitude frente aos fenômenos, porque nele o indivíduo evita qualquer a afirmação ou negação sobre a realidade, deixando que a realidade se mostre à consciência do sujeito a partir de sua abertura intencional. Como afirma Husserl (2001, pp. 5253):

$\mathrm{O}$ que acontece aqui pode também ser descrito da seguinte maneira: Se dizemos do eu que percebe o "mundo", e aí vive de forma totalmente natural, que ele está interessado nele, então teremos, na atitude fenomenologicamente modificada, um desdobramento do eu; acima do eu ingenuamente interessado no mundo estabelecer-se-á como espectador desinteressado o eu fenomenológico. Esse desdobramento do eu está por sua vez sujeito a uma nova reflexão, reflexão que, por ser transcendental, exigirá uma vez mais a atitude "desinteressada do espectador", preocupado somente em ver e descrever de maneira adequada.

A partir desse giro de percepção possibilitado pela fenomenologia de Husserl, seu aluno e discípulo heterodoxo, Max Scheler, afirmará que os valores também são objetivos, isto é, que eles não são meras invenções ou abstrações do sujeito, mas se mostram de forma intencional à consciência humana. Dito de outra maneira, Scheler afirmava que se o indivíduo analisar a realidade material a partir da fenomenologia, esta realidade material mostrará certos valores ao sujeito. Como afirma Costa (1996, p. 16):

Scheler afirma taxativamente que as essências são percebidas intuitivamente e não fabricadas pelo sujeito. [...] Max Scheler se destacou pela maneira pessoal e original de entender a fenomenologia e o seu método, adaptando e desenvolvendo a proposta husserliana, voltada para a análise da intencionalidade da consciência como único caminho seguro para se alcançar a verdadeira objetividade.

Desse modo, é a partir desse substrato teórico da fenomenologia de Husserl e de Scheler, que Viktor Frankl afirmará que o sentido da existência - assim como a percepção das coisas e assim como os valores - não é mera invenção abstrata do sujeito, mas parte da própria realidade concreta. Quando o ser humano retorna à realidade mesma, deixando-se indagar por ela, esta o apresenta um apelo. E sua resposta a este inquérito da realidade é o que configura Complexitas - Rev. Fil. Tem., Belém, v. 5, n. 1 , p. 67-79, jan./dec. 2020 - ISSN: 2525-4154 
sentido à sua existência.

Com essas afirmações, Frankl quer demonstrar que o sentido da existência deve ser descoberto pelas pessoas no próprio mundo, na própria realidade, e não tanto dentro de si mesmas, como se elas fossem um sistema fechado (FRANKL, 2019, p. 135). Segundo ele, o ser humano já é um ser em relação de abertura com o mundo, daí sua capacidade de encontrar sentido para sua vida quando se abre a uma realidade que é distinta a ele mesmo. A essa atitude abertura à realidade, capaz de dar sentido à vida, Frankl chamou de autotranscendência:

\begin{abstract}
(...) entendo por autotranscendência o fato antropológico fundamental de que o ser humano se remete sempre, mais além de si mesmo, a algo que não é ele: a algo ou alguém, a um sentido que o homem busca ou a um semelhante com quem se encontra. E o homem se realiza si mesmo na medida em que se transcende: ao serviço de uma causa ou no amor a outra pessoa. Em outras palavras, o homem só é plenamente homem quando se sacrifica por algo ou se entrega por outro. E é verdadeiramente homem quando se deixa em segundo plano e se esquece de si mesmo. (FRANKL, 2009, pp. 62-63, tradução nossa)
\end{abstract}

Neste sentido, dentre as várias formas que o ser humano pode encontrar em sua existência para abrir-se a uma realidade que não é ele mesmo, Frankl as reúne em três atitudes fundamentais: 1) dedicar-se a um trabalho ou a pratica de algo; 2) experimentar algo ou amor de alguém; 3) enfrentar um destino inevitável e fatal com atitude de firmeza (FRANKL, 2019, p.135).

E é nesta última atitude apresentada por Frankl que a realidade do tédio na pandemia e na quarentena pode ser encarada. Pois, longe de ser uma situação que deve ser expurgada e eliminada do cotidiano, o tédio mostra-se na verdade como a oportunidade de deixar-se interpelar pela vida. A partir do tédio, o ser humano pode resgatar em sua existência a atitude da responsabilidade diante da vida, entendendo aqui "responsabilidade" como a atitude de responder as interpelações que a própria vida nos suscita.

Que nos aponta a realidade do tédio? O que a realidade da pandemia e da quarentena espera de nós? Que ações elas nos apresentam como apelo? Respondendo a estas questões, o sofrimento atual pode apresentar-se como um sofrimento com sentido, e assim, a responsabilidade e a liberdade nos são devolvidas mesmo em uma situação de isolamento social e privações. Como afirma Frankl (2019, pp. 89-90):

A liberdade espiritual do ser humano, a qual não se the pode tirar, permite-lhe, até o último suspiro, configurar sua vida de modo que tenha sentido. Pois não somente uma vida ativa tem sentido, em dando à pessoa a oportunidade de concretizar valores de forma criativa. Não há 
sentido apenas no gozo da vida, que permite à pessoa realizar valores na experiência do que é belo, na experiência da arte ou da natureza. Também há sentido naquela vida que - como no campo de concentração - dificilmente oferece uma chance de se realizar criativamente e em termos de experiência, mas que lhe reserva apenas uma possibilidade de configurar o sentido da existência, que consiste precisamente na atitude com que a pessoa se coloca face à restrição forçada de fora sobre seu ser. Faz muito que o recluso está privado de realizar valores criativos. Mas não se encontra sentido apenas na realização de valores de criação e experiência. Se é que a vida tem sentido, também o sofrimento necessariamente o terá. Afinal de contas, o sofrimento faz parte da vida, de alguma forma, do mesmo modo que o destino e a morte. Aflição e morte fazem parte da existência como um todo

Sendo assim, a situação de privação da experiência criativa durante a quarentena, aliada ao tédio, não podem significar o fracasso existencial para as pessoas. Pois tal como a reflexão de Frankl mostrou: se é que a vida tem sentido, também o tédio necessariamente o terá. Basta que nos deixemos interpelar pelo mesmo e, a partir disso, responder ao apelo que brota da própria vida, da própria realidade.

\section{CONSIDERAÇÕES FINAIS}

As reflexões filosóficas sobre o tédio, além das considerações da logoterapia de Viktor Frankl sobre a questão do sentido da existência, revelam que as sensações de frustração e vazio existencial relatadas por muitas pessoas neste período de quarentena por conta da pandemia do COVID-19 podem ser encaradas a partir do que Frankl chamou de "noodinâmica". Em outras palavras, faz-se necessário que o ser humano atual tome consciência de que a dinâmica entre o que esperamos da vida e o que de fato já conseguimos realizar - a dinâmica entre o real e o ideal - deve provocar a pergunta pelo sentido da existência. Em outras palavras, o tédio experimentado por muitas pessoas nesse período de quarentena deve ser vivenciado não como o sinal objetivo do fracasso dos projetos existenciais, mas como uma provocação feita pela realidade concreta, provocação esta que interpela o ser humano quanto ao sentido que sua existência está tomando.

Frequientemente as pessoas tomam a questão do sentido da vida como o produto de uma reflexão abstrata ou como uma regra geral imposta por realidades externas (cultura, tradições, etc). No entanto, a grande contribuição de Frankl foi mostrar, por meio da fenomenologiaexistencial da logoterapia, que na verdade o sentido não é inventado pelo individuo ou por uma tradição, mas ele se mostra, revela-se a partir da realidade mesma. Realidade esta que, sendo uma realidade de positiva de criatividade ou uma situação de sofrimento irremediável, sempre 
questionará o individuo, provocando-lhe a dar uma resposta. Esta resposta, quando dada a partir da "autotranscendencia", é capaz de conferir a sentido à realidade mais difícil, inclusive a realidade desconcertante do tédio.

\section{REFERÊNCIAS BIBLIOGRÁFICAS}

CHALET, Aline. Depressão $e$ ansiedade aumentaram até $80 \%$ na quarentena, diz pesquisa. Disponível em:

https://noticias.r7.com/saude/depressao -e-ansiedade-aumentaram-ate-80-naquarentena-diz-pesquisa-22072020

Acessado em: 13 de Setembro de 2020.

COSTA, J. Max Scheler: o personalismo ético. São Paulo: Editora Moderna, 1996.

FERREIRA, Aurélio. Mini Aurélio século XXI escolar. Rio de Janeiro: Editora Nova Fronteira, 2001.

FRANKL, Viktor. El hombre doliente. Barcelona: Editora Herder, 2009.

\section{Em busca de}

sentido. $46^{\mathrm{a}}$ Ed. Petrópolis: Editora Vozes, 2019.

FROMM, Erich. La vida auténtica. Barcelona: Paidós, 2007.

HUSSERL, Edmund. Conferências de Paris. Tradução de Artur Morão, António Fidalgo. Lisboa: Ed. 70, 1992.
- Investigaciones Lógicas. Madrid: Revista de Occidente, 1976.

cartesianas: $\quad$ introdução $\quad$ àtações fenomenologia. Traduzido por Frank de Oliveira. São Paulo: Editora Madras, 2001.

LYOTARD, Jean-François. $\quad L a$ condición postmoderna. Madrid: Editora Informe sobre el saber, 1984.

MOTA, Thais. Pesquisa revela problemas de sono, alimentação $e$ saúde mental durante pandemia. Disponível em: https://www.otempo.com.br/interessa/p esquisa-revela-problemas-de-sonoalimentacao-e-saude-mental-durantepandemia-1.2343916 Acessado em: 13 de Setembro de 2020.

SVENDSEN, Lars. Filosofia do Tédio. Rio de Janeiro, Jorge Zahar, 2005.

TORRALBA, Francesc. ¿Por qué Pierre Anthon debería bajar del ciruelo? Interioridad y sentido. Barcelona: Khaf, 2013.

BRAGA, A. R. P. Tédio e Sentido na Pandemia: Uma Análise a Partir do Pensamento de Viktor Frankl.Complexitas - Rev. Fil. Tem. Belém, v. 5, n. 1, p. 67-79, jan./dec. 2020. Disponível em: http://www.periodicos.ufpa.br/index.php/complexitas/article/view/9323>. Acesso em: 01 de novembro de 2020. 